\title{
Top 10 Key Skills in Olympiad in Informatics
}

\author{
Marina S. TSVETKOVA ${ }^{1}$, Vladimir M. KIRYUKHIN ${ }^{2}$ \\ ${ }^{1}$ Academy of Natural History, Russian Federation Russia, Moscow, 105037, box 47 \\ ${ }^{2}$ Dept. of Informatics and Control Processes, National Research Nuclear University "MEPhI" \\ 31 Kashirskoe Shosse, Moscow 115409, Russian Federation \\ e-mail:ms-tsv@mail.ru,vkiryukh@gmail.com
}

\begin{abstract}
This article presents the methodological experience of 30 years of work on the preparation of International Olympiad in Informatics (IOI) medalists from Russia, based on the great contribution of the IOI community to the development of the syllabus IOI, criteria for the success of students and the collection of IOI tasks for 30 years of its implementation. Based on the experience of the authors of the article on the preparation in Russia of gold medalists IOI and the curriculum of school informatics are presented 10 IOI key skills as criteria for the medal success of students at IOI.
\end{abstract}

Keywords: school informatics, International Olympiad in Informatics, computer science curriculum, Olympiad training, Olympiad skills, General school competences.

\section{Introduction}

The support of talents in Informatics is an important vector of the development of the education system in the 21 st century, which is the beginning of the digital era, the digitalization of professions, when Informatics becomes the third literacy in the education of children and requires scientific and methodological study by the efforts of all IOI countries. This is so, since IOI in 1989 was start with the support of UNESCO as a main point for the promotion of school Informatics in all educational systems of the world as a fundamental knowledge.

Over the 30 years of its development, IOI has made a huge contribution to the development of the curriculum of school Informatics, preserving the fundamental core of the subject as computer science. The formation of syllabus IOI in the 90 s allowed to form a modern view of computer science in school as a science-intensive discipline, did not allow to rebuild school computer science as a course with computer applications. Currently, there is a digitalization of professions, more and more highly qualified it professionals are required, but the core of their training is the computer science. And the development of the school course of Informatics with the preservation of the fundamental core - as its basis - has become the norm for the education systems of the world. But 
it requires highly qualified teachers at school (Kiryukhin and Tsvetkova, 2010), and also because of the role of computer science as a literacy program-mandatory inclusion of the course continuously from primary school. This will create an accessible environment for the formation of common competencies for all children of the country in step with the times, as well as provide an opportunity to integrate into any training and vocational education digital component at the current level.

\section{The Role of IOI in the Development of School Informatics Course for the World}

The role of IOI and was manifested in the methodological direction: creating an accessible Olympic Lift in Informatics (Kiryukhin and Tsvetkova, 2014), for support of talented children on Informatics in countries. Since the establishment of the IOI conference and the formation of the open scientific electronic library Olympiad of Informatics in the form of a scientific journal IOI allows all countries to focus on the experience of other, not to waste time on opening a methodological path taken already by other countries, and actively transform the existing collective expertise in each country, taking into account the specifics of educational systems in them. It is the availability of scientific and methodological achievements in the IOI environment that allows countries to focus on the level of achievements that the country needs, not only on individual achievements in the medal series of the highest dignity, but in the training system, that:

- Allows the country to form an annual team of 4 members.

- Show good result by all team members.

- To have leaders in the team with a Medal result.

- To go to the best students of the school Olympiad on professional competitions of programmers from universities, and then from the leading it companies.

This Olympic Lift is the actual engine of the development of school programs in Infiormatics in all countries of the world, IOI has become a real environment for the career growth of talented computer scientists and forms a global human potential for the development of digital civilization, and the contribution of IOI is invaluable and leading in this career lift for hundreds of IOI participants who have become an international top community of professionals ensuring the success of it companies. For 30 years, more than 6,000 children from countries from all continents of the world have received the highest experience of preparation and participation in IOI, the community of organizers has launched the Olympiad movement in Informatics in their countries, starting from primary school, motivating children in the it field.

In addition, the IOI community of trainers from countries around the world has collectively formed the content. IOI is the best in the world and is the benchmark for national computer science Olympiads, being an open live textbook for children and mentors.

Now IOI is already a world leader in the development of accessible sports environment for the children of the world, opening content tasks, including its open cloud sys- 
tem events, projecting IOI experience in the world, which opened the Internet contest as training for the IOI, creating a continental Olympics for the staging controversial practices children and engages in Olympiad movement more talented kids around the world! The contribution of IOI is also the contribution of each participating country, which directs forces within the country to the development of school Informatics and is included in the partnership with countries for various events: summer camps, distance training, internships for coaches and mentors of Olympiad Informatics.

All these achievements of IOI show that IOI is a global educational and social movement of children, coaches, scientists and mentors in the field of it, which promotes the international community of scientists and methodologists, teachers and specialists of educational systems of the world, IOI remains out of politics, demonstrates the highest level of political correctness and has established itself as a public scientific movement, where the countries conducting IOI-provide a serious financial contribution to its implementation and dissemination of new achievements in Informatics.

Of course, each country has its own specifics of the education system, but it is IOI that unites countries to identify common scientific approaches to identify new methods of Olympiad Informatics and systematic approaches to the development of talents in the field of Informatics.

\section{IOI Skills as Important Life Skills in the Professional Future of the Kids}

The school Informatics course as IT-literacy is the basis for the Olympic lift (Kiryukhin, 2010). The sooner a child gets access to school Informatics the sooner he will be able to choose for himself the Olympic track. The basis of the Olympic lift is Olympic syllabus (Kiryukhin, 2007), it forms the profile skills, and is the Foundation of intellectual training. It is important that the first start-up in Informatics was given to every children by school, a primary school course in Informatics in 6-12 years old (Tsvetkova, 2016), motivating children in the subject, forming primary informatics literacy, based on the formation of the child's algorithmic, logical, analytical, critical, modeling, heuristic thinking, computer and computational skills, and structural memory, involving in children's competitions in Informatics in School. The development of these types of thinking and structural memory can provide Olympiad Informatics, the Foundation of which is the Syllabus IOI as profile skills in informatics literacy.

Thus it is necessary to allocate three stages of development of children in the Olympic Informatics: start-up for younger 6-12 years old, basic level for juniors 13-15 years old and advanced level for children 15-18 years old, organically to build preparation according to age and needs of children.

For each stage, a development benchmark is proposed - the development horizon, as the highest bar of achievement for each age. And the IOI community has formed all three landmarks: start up tasks (Kiryukhin and Tsvetkova, 2016), Olympiad Beavers, Junior EJOI and profile level IOI. Many National, local and regional Olympiads have become stations to test the potential of Olympians in their preparation for IOI as the world's most important Informatics Olympiad for schoolchildren. 
The Olympiad track will become a portal to the it profession for all participants of the Olympiad in Informatics, regardless of the result. It is important for children to understand that their training and participation in IOI is their baggage, experience that gives them a high potential for further realization of themselves in the it profession. When we talk about the key skills in Olympiad Informatics, we mean first of all life experience and skills for the future of each child, his self-realization as a strong personality, ready to develop in the it sphere continuously.

Therefore, the top 10 skills of Olympiad training in computer science is the way to the adult future of children, some of which can show a medal result. The higher the independence of the child in preparation, commitment to the horizon of its development, perseverance and hard work, the higher its result IOI. In fact, 10 skills is a guarantee of success in training. It is important that children know about this, as the entire methodological base and practical environment of Olympiad Informatics with online tours and competitions of different levels is formed in the world and is open to children thanks to the community of IOI countries.

What skills need to be formed in the Olympiad training in computer science to maximize the child's professional growth and performance? Attention, all these skills are based on the motivation of children, their desire to work independently. If at the stage of startup the main role in training is played by the teacher of Informatics and coaches, then for juniors this balance is $50 \%-50 \%$, and for the senior group, the profile training coach performs a consulting function, the main work should be carried out by the student himself, and regularly, without failures in training, it is better every day, as do people of art and sports.

Consider the model categories of competences in the school education system and how to integrate children 's creative development into them. There are three categories of competences: to know, to be able and to apply (in practice, in life). Different accents in this system triad allow you to form different training techniques.

The knowledge approach relies on theoretical knowledge, analytical thinking, the development of intelligence, memory (to know). The practical approach relies on functionality, practical skills based on samples, encouraging productive experience (to be able). The activity approach is based on the development of self-reliance in the application of acquired knowledge and skills in life, encourages self-study and emphasizes creative initiatives of the child (to apply in practice, in life).

In the context of an information society based on dynamically changing knowledge, all three categories of competence in school education have received a new view of teachers. Thus, functional literacy (to know, to be able) based on knowledge and skills in industrial society has been replaced by a paradigm developmental teaching based on creativity and on the development of the capabilities of each child (to know, to be able and to apply in practice, in life).

The success of a person in the profession is largely laid down by school life. In developmental teaching it is necessary to reveal the creative personality, from early childhood to develop it and give an opportunity to self-realization in the zone of interests of the child. That is, the school of developmental teaching relies on the creativity 
of the child, as much as possible contributes to his creative development. (Kiryukhin and Tsvetkova, 2011).

Methods of realization of creative potential of children traditionally are various competitions and Olympiads. Undoubtedly, for children motivated in informatics, one of such spheres of realization of creative potential is the national Olympiad in informatics and its highest manifestation - IOI.

It should be taken into account that in addition to general school education, the development of creativity is based on the development of the talent of the child in a certain sphere of creativity and requires the reflection of the specifics of creativity. It is possible to see that the main categories of child developmental teaching in Olympic preparation also are to know, to be able, to apply. However, in this training it is necessary to know the theoretical component of the sphere of creativity, to be able and to possess in perfection the instruments of creativity, to have practical experience of self-realization in the sphere of creativity in the public environment in open competition for recognition and search for ways of improvement. The methodologies developmental teaching these competencies vary. The trainer 's technique of Olympic preparation depends on how the trainer places emphasis in development of these competences, as their combination will provide.

Since each creative environment has its own specificity, in Olympic preparation for IOI it is necessary to take into account this specificity. In the general usual categories of competences to know, to be able, to apply independently it is possible to distinguish 10 key competences taking into account the specifics of IOI. At the same time, $10 \mathrm{key}$ competences reflect the specifics of IOI for the development of creative activity and, as a result, the realization of children in IOI.

Can be considered 10 key skills IOI - steps of development, which will allow the child to become strong in IT, his important life experience relevant Informatics as a student, but this experience - a motor for future training and professional development. We understand that IOI despite the high level of complexity - learning environment for children's growth in science. And ahead - the real ore in the IT sphere, the innovative way of our planet in the digital environment of its development, where you need a lot of highly professional in IT. And that's the mission of IOI and everyone who works with kids in Informatics, from the school teacher to the coaches and the IOI science community.

\begin{tabular}{lll}
\hline $\begin{array}{l}\text { Category of the general } \\
\text { competences }\end{array}$ & Specifics of IOI & IOI key skill \\
\hline To know & IOI syllabus & $\begin{array}{l}\text { 1/Subject-specialized competencies } \\
\text { 2/Algorithmic competence } \\
\end{array}$ \\
& & 3/Learning competencies (the ability to learn) \\
& IOI tasks archive & 4/Practical competences (qualification) \\
To be able & & 5/Instrumental competencies (Programming tools) \\
& & 6/Digital competencies \\
To apply independently & Experience of realization & 7/Technological competence \\
& of personal potential in the & 8/Communicative competence \\
& Olympiad in Informatics & 9/Technical competence \\
& National OI, IOI, ets & 10/Creative competencies \\
\hline
\end{tabular}




\title{
4. Top 10 Key Skills for the Success of Students in IOI Preparation
}

\author{
What you need to know, and be able to apply in their practice the child in Olympiad \\ Informatics?
}

$\begin{aligned} & 10 \text { key skills } \\ & \text { in Olympiad } \\ & \text { in Informatics }\end{aligned}$

Subjectspecialized competencies

Algorithmic competence

Practical competences (qualification)

Learning competencies (the ability to learn)

Instrumental competencies (Programming tools)

\section{Deeply know the tools of} his creativity in Olympiad Informatics-know the technology of programming, understand the semantics of the programming language

Digital competencies Syllabus topics

To know the specifics of IOI problems, own various aspects of algorithmic approaches to the specifics of IOI problems on the example of the collection of IOI problems IOI tasks from the collection
I online programming,
ToknowIOIsyllabus, including, To study the theory of sec- To analyze the completeness what topics and sections are tions of the IOI syllabus, to of knowledge of the IOI included in the IOI syllabus, to compare the problems of the Syllabus, to apply the theory understand the reflection of the Olympiad and the topics of comprehensively in solving the IOI Syllabus in the tasks of the the IOI Syllabus, plan your problems of the Olympiad Olympiads, to think about the theoretical training, identify level of your mastery of the IOI and eliminate deficiencies in theoretical training

To be able to solve IOI prob- Conduct analysis of tasks, to lems, to be able to analyze speak to the audience with the the problem and compare it analysis, in practice to assess with the IOI syllabus the complexity of the algorithm for solving the problem, subtasks

Know about the Collection of Be able to plan your daily To cultivate the will to win, to IOI tasks, know about online workout using the IOI achieve the solution of each

task collection as a basic problem by 100 points, to train workout for mastering the for the speed of solving the IOI syllabus problem

know about mass open Be able to learn online To plan in the preparation online courses on Olympiad courses algorithms and movement forward (positive Informatics, distance learning programming, to develop dynamics of development), to systems on algorithms and erudition in the choice of cover new and more difficult MOOCs on the topics of courses, critically to estimate Syllabus IOI experience of continuous development, training and the growth in the Olympic preparation

The most complete know- To develop skills and practice ledge of the fundamental tool in different programming of Olympiad Informatics- languages and software enviprogramming language $\mathrm{C}++$ ronments, to develop erudition and additional programming in programming languages, languages (for IOI) their purpose and distinction, to follow the innovations

To know the features of com- Own a computer, operating Apply digital competencies puter configuration, to know system and software without in the workplace in any envithe requirements for memory barriers, be able to freely ronment of computer support of and time limits for the program, navigate and work in an the Olympiad, show motivation to understand and understand online environment, in a in their technical training, taking the information structures and network based on analogues into account new computer and methods of their processing of the IOI competition network technologies on the computer, taking into system account its configuration 
Table continued from previous page

$\begin{aligned} & 10 \text { key skills Know, understand, think } \quad \text { Be able to do, plan, evaluate } \begin{array}{l}\text { Apply in their practice, } \\ \text { creativity, analyze the results }\end{array} \\ & \text { in Olympiad } \\ & \text { in Informatics }\end{aligned}$

Technological Know about international and To be able to analyze the On experience to form techcompetence national local competitions: results of each participation nological skills of participation (experience for example, EJOI, IAITI, in the competitions for com- in the international, national, of realization USACO, APIO, Top Coder, pleteness of the decision, local competitions, to form of personal etc., methods of self-assessment the speed of the decision, psychological stability to the potential in the Olympiad in Informatics) of training results, think about to identify the results of stressful competitive environand critically evaluate their the competition deficits ment, to form confidence in the results, understand and evaluate in training on the topics competitive ability their deficiencies in training of the IOI syllabus, to be and think about, plan ways to able to design the results of eliminate them performances and perform individual short-and longterm self-training plans

Communica- Know the basics of communi- Be able to work in English To put into practice commutive cation technologies, informa- withtexts,incommunication, competence tion security requirements in the communication environment

in online courses

Be able to speak on the topic of Olympiad Informatics, formulate questions

colleagues

Technical competence

Creative competencies

Know the technical resources to equip the Olympiad envispecifics of the information system of competitions, methods of work in these environments

Be able to develop highspeed and high-quality aspects of working with devices on the computer and with software,

Be able to independently use and configure the necessary software ronment in Informatics, the

Full understanding of the The ability to independently Practice self-development tasks structure of the Olympiad task, solve problems for a full (composed of tasks) based on the the features of the formulation score, the ability to inde- composition of skills: selection of the problem in the task and pendently compose Olym- of algorithmic problems its formalization, restrictions piad tasks and their full in IOI syllabus, essay text for subtasks, the specifics preparation for the tour (IOI tasks in problem formulation, of the development of tests analogues)

and debugging, methods of formation of the evaluation system work with sources, online courses, in the collective enIn practice, continuous monitoring of new versions of software, to analyze their differences and features in operation development of tests for this problem, the installation problem in the system events tour on the author's task for other students, participation in and development of the assessment system, conducting analysis tasks. 


\section{Indicators of Achievement of 10 Key Skills in IOI}

\begin{tabular}{|c|c|c|c|}
\hline $\begin{array}{l}\text { Indicators for } 10 \text { key } \\
\text { skills in IOI }\end{array}$ & $\begin{array}{l}\text { Indicator for stage-start up } \\
\text { (7-12 years old) }\end{array}$ & $\begin{array}{l}\text { Indicator for stage juniors } \\
(13-15 \text { years old })\end{array}$ & $\begin{array}{l}\text { Indicator for stage 2-profile } \\
\text { level ( } 15-18 \text { years old) }\end{array}$ \\
\hline $\begin{array}{l}\text { ialized } \\
\text { s }\end{array}$ & $\begin{array}{l}\text { Proficiency in IOI Syllabus } \\
\text { topics based on the quality } \\
\text { of tasks from the IOI } \\
\text { collection by training level } \\
\text { with achievement of a } \\
\text { critical score: } \\
\text { At least } 30 \text { points for each } \\
\text { task for } 2 \text { hours per task }\end{array}$ & $\begin{array}{l}\text { Proficiency in IOI Syllabus } \\
\text { topics based on the quality } \\
\text { of tasks from the IOI } \\
\text { collection by training level } \\
\text { with achievement of a } \\
\text { critical score: } \\
\text { At least } 60 \text { points on avera- } \\
\text { ge for three tasks in } 2 \text { hours } \\
\text { per task }\end{array}$ & $\begin{array}{l}\text { Proficiency in IOI Syllabus } \\
\text { topics based on the quality } \\
\text { of tasks from the IOI } \\
\text { collection by training level } \\
\text { with achievement of a } \\
\text { critical score: } \\
\text { At least } 75 \text { points on avera- } \\
\text { ge for three tasks in } 2 \text { hours } \\
\text { per task }\end{array}$ \\
\hline $\begin{array}{l}\text { Algorithmic } \\
\text { competence }\end{array}$ & $\begin{array}{l}\text { The number of tasks } \\
\text { from the IOI collection } \\
\text { (performed on a critical } \\
\text { score) per year is not less } \\
\text { than } 10\end{array}$ & $\begin{array}{l}\text { The number of tasks } \\
\text { from the IOI collection } \\
\text { (performed on a critical } \\
\text { score) per year is not less } \\
\text { than } 20\end{array}$ & $\begin{array}{l}\text { The number of tasks } \\
\text { from the IOI collection } \\
\text { (performed on a critical } \\
\text { score) per year is not less } \\
\text { than } 30\end{array}$ \\
\hline
\end{tabular}

Practical competences (qualification in IOI)

Learning competencies (the ability to learn)

Instrumental competencies (programming tools)

The number of tasks solved The number of tasks solved The number of tasks solved in a year, modified to a full in a year, modified to a full score - at least 10 score - at least 20 in a year, modified to a full Number of online courses Number of online courses Number of online courses for this training group per for this training group per for this training group per year is $1-2$ year is 3 year is $3-5$

Number of courses in C++ Number of courses in pro- Number of courses in proprogramming language at gramming languages at gramming languages at least 1 least 2 least 3

Number of courses in $\mathrm{C}++$ Number of courses in $\mathrm{C}++$ programming language at programming language at least 1 least 1

Speed of solving IOI collection problems in $\mathrm{C}++$ per critical score no more than 1 hour per 1 task

Digital competencies

Assessment of software Assessment ownership Evaluation software ownerproficiency under Linux OS software under OS Linux ship under Linux OS (Yes, (mastered common tools in (not fully, can work on full ownership) Linux OS) Olympics under OS Linux)

Technological competence

Communicative competence

Number of online tours or Number of online tours or Number of online tours or competitions- 1 each month competitions- 2 each month competitions- 3 each month

The average score for tours and competitions per month is not less than the critical score for the preparation group

The level of understanding The level of understanding The level of understanding of the interface of the sys- of the interface of the sys- of the interface of the system of competitions in tem of competitions in tem of competitions in English: "I Understand English: "I Understand, English: "I Understand partially"

Level of understanding of Level of understanding of the text of tasks in English, the text of tasks in English, online courses in English (I online courses in English understand partially) (full) 
Table continued from previous page

\begin{tabular}{|c|c|c|c|}
\hline $\begin{array}{l}\text { Indicators for } 10 \text { key } \\
\text { skills in IOI }\end{array}$ & $\begin{array}{l}\text { Indicator for stage-start up } \\
\text { ( } 7-12 \text { years old) }\end{array}$ & $\begin{array}{l}\text { Indicator for stage juniors } \\
\text { (13-15 years old) }\end{array}$ & $\begin{array}{l}\text { Indicator for stage 2-profile } \\
\text { level ( } 15-18 \text { years old) }\end{array}$ \\
\hline Technical competence & $\begin{array}{l}\text { The level of knowledge of } \\
\text { the technical capabilities } \\
\text { of the competition system: } \\
\text { training, work with external } \\
\text { technical support and advice } \\
\text { of the coach }\end{array}$ & $\begin{array}{l}\text { The level of ownership } \\
\text { of the system of the } \\
\text { competition: possess, can } \\
\text { be issues when moving to a } \\
\text { new system of competition } \\
\text { takes time to adapt }\end{array}$ & $\begin{array}{l}\text { The level of ownership sys- } \\
\text { tem contest: possess freely, } \\
\text { can on their own quickly } \\
\text { adapt to any system contest } \\
\text { for negligible time }\end{array}$ \\
\hline Creative competencies & $\begin{array}{l}\text { Participation in the task } \\
\text { development group with } \\
\text { a coach, experience of } \\
\text { participation-at least } 1 \text { task } \\
\text { per year }\end{array}$ & $\begin{array}{l}\text { The Number of tasks fully } \\
\text { developed in a group with a } \\
\text { coach like IOI for training } \\
\text { tours in their training } \\
\text { team - at least } 2 \text { tasks per } \\
\text { year }\end{array}$ & $\begin{array}{l}\text { The number of tasks fully } \\
\text { developed in a group } \\
\text { without a coach like } \\
\text { IOI for training tours or } \\
\text { competitions-at least } 2 \\
\text { tasks per year }\end{array}$ \\
\hline
\end{tabular}

\section{Role of Head Coach for the IOI National Team's Olympic Training}

Personal experience as the head coaches of the Russian national team from 1989 to 2018 allowed us to find ways to guarantee the success of children participating in IOI in practice.

First, let's list what the head coach is responsible for:

- The final result.

- The organization of the training process.

- Potential growth in the preparation of participants (together with teachers, mentors and coaching staff).

- Building a long-term plan for each stage of training (for 3 years) for each participant.

- The team's psychological readiness to perform successfully.

- Basic IOI-specific training (i.e. the minimum IOI-specific qualification level is the individual training plan of each participant and the quality of its implementation by the participant).

- Long-term planning in the framework of new trends in Olympiad Informatics.

- The team selection methods based on objective results (indicators) of the participant's preparation, taking into account the achievement of the qualification minimum according to IOI specifics.

- The formation of basic training for juniors as a shift to the senior team.

Often coaches, especially those who are unfamiliar with pedagogy and school work, focusing on the professionalism of students, do not take into account the full readiness of the participant for the specifics of the competition, believing that any competition will have an effect. This is not only wrong, but also harmful for children, since the spread in different competitions takes a lot of effort from the participant and does not allow them to prepare for medals based on the specific specifics of the target competition. 
In order for participants to grow, they must first be taught to train well, and it is the Junior stage that is aimed at this task.

You need to start in a timely manner, since entering the Olympiad qualification as a training base from the age of 16 will not give the desired effect due to lack of time, since the qualification is specific to a specific Olympiad. A Junior progresses only when he goes through a well-thought-out, well-targeted training within a well-organized training process. Target training, or qualification training - is a painstaking daily work, training on the IOI tasks archive (IOI, 2019) as is customary for musicians, artists, and daily sport training or art etudes. The IOI archive is such mandatory etudes or daily training sessions for preparing for IOI.

There is a common misconception that participants allegedly grow during participation in various competitions. This is not true. In the competition, they only demonstrate what they have accumulated over many days during hard training. And if there is no good training process, or if the participant himself for some reason does not work well or is not motivated to succeed, then he does not show high results in the competition. Frequent participation in competitions indiscriminately, mixing of specifics in competitions without targeted training leads to fixing the participant's incomplete result on the tasks of the competition, no higher than 50 percent of points and lack of perseverance in training. As a result, the opposite effect is fixed - the inability to work for a full score, the highest result and the unwillingness to hone it in independent constant work. You need to learn how to get a high result, and most importantly, do it at the Junior stage, so that there is time to improve the participant at the peak of his capabilities, that is, to open the child to take off to his own capabilities.

Talent plus every day work is the key to the success of any participant. The presence of talent can be recognized by an expert look and the first performances in national Olympiads of children.

But, unfortunately, many gifted participants believe, or have been given the wrong installation by their personal trainers, that it is enough for them to perform on one talent, watch and listen to others, but not necessarily do something themselves. They expect enlightenment by training irregularly and not full strength.

You can achieve real success only through colossal, regular, daily work and a deep passion for the subject of the Olympiad. All those who become IOI stars work hard on themselves for a long time. We can say that the key to improving talent is the balance of coaching and independent work 50-50. If you do not teach the child to organize their own regular work to improve their talent, they will show the same 50 percent of the result. And if at the Junior stage the coach's participation prevails, then at the Junior stage this balance must be clearly carried out, then at the stage of the senior group motivated independent work prevails and this is the key to full results.

Take examples of IOI participants who were at the peak for 3-5 years, at the top of IOI, who became absolute Champions twice or more times. Behind these achievements is a daily, passionate, correct training work. In teams where the medal result of all team members in each IOI year is shown, such work is built. It is important to analyze the statistics of such achievements of countries and take into account their experience. 
Concentration of attention, discipline of the training mode, high motivation, deep training, independence and perseverance-all this should be brought up in the participant from an early age and taken into the work of the head coach, then you can plan the growth of the success of talented children to the level of their potential opportunities for everyone, and this should be a guideline for the medal result. With these opportunities and important experience, children will go further into professional life.

\section{Methodology of the Basic Qualification Olympiad Preparation of the IOI National Team}

How to plan regular, daily work-basic (qualification) training of the Olympiad preparation? The difference between the basic qualifications is that it is an invariant core of training that is common to all participants, in addition to its variable individual trainings that take into account the child's personality and potential.

Basic training as a qualification, mandatory for all participants in preparation for the international Olympiad, can be represented by a three-level system.

The training is conducted on the tasks of the archive of the Olympiad that the participant is preparing for. We will look at the IOI goal. Basic training for IOI is conducted in two-week cycles, each cycle includes thematic training sessions and tours on IOI tasks on the topic.

The basic training curriculum for each age group of training is designed based on the IOI syllabus topics.

Cycle tours have different specifics, but are intended for all age groups: primary group 7-12 years old, junior group (13-15 years old)? Senior group (16-18 years old). For all age groups:

1. Thematic tour with a selection of problems on a specific topic from Syllabus IOI with a preliminary lecture on this topic.

2. A validating tour for knowledge of the specifics of tasks from different topics, using a ready-made tour of the year from the Olympiad archive (IOI or at the choice of the coach from similar competitions) with a preliminary overview lecture on the topics in the tasks of the tour.

3. A control tour, such as a type 1 and type 2 tour with a final lecture after the tour.

Children should not be divided into classes based on age. The complexity of the task of tours is regulated for the groups, but all classes are held together.

Cycle for 2 weeks of training. For 2 hours a day, the day of the tour for the allotted number of hours is recommended to be spent on an extra-curricular day at school.

\section{First week, 6 days.}

- Days 1-2, (2 days) 4 hours. Lecture on the theory, on the topics of IOI syllabus, for which the tasks for the tour are selected from the archive of IOI (or other Olympiads). 
- Day 3, (one day). Conducting a tour on 2-3 tasks for 3-4 hours, respectively. For different age groups, tasks are selected from the corresponding difficulty tour, and the achievement of a critical score for the age group is recorded. Primary group have one task for 2 hours, junior group have two tasks for 3-4 hours, and senior group have 3 tasks for 4 or 5 hours.

- Day 4 (one day), 2 hours. Selection of algorithms for solving problems of the tour. The analysis is carried out in two stages. First, the participants with the best results come forward and explain their solution. Then the trainer shows the reference solutions for the full score . only then- explanation or final lecture of the theory of Syllabus IOI on the example of a reference solution of the task.

- Day 5 (one day), 2 hours. Repeat the tour on the same tasks for 1 hour for juniors and for seniors groups. The participant must not see their decisions and repeats the tour again, but for what time. This will show the effects of absorption of the solutions at the critical point and above, speed and quality. Often this tour reveals the technical and instrumental, fault intellectual deficits of the participant's training.

- Day 6, (one day). Individual consultation with the coach. 1 hour. Filling in the individual plan by a student with a self-assessment of all indicators for the week. Assignment of 3 tasks from the Olympiad collection by the coach for independent study and trial solution in 6 days. Tasks are selected either by the passed topic (for any age group) or as a tour of the year from the archive with self-analysis of the Syllabus IOI topics of these tasks (for juniors and seniors).

It is not necessary to select separate tasks for the Primary and Junior age groups. All IOI tasks have different solution levels, separated by subtasks and provided with points. For each age group on the same tasks in the allotted time, it is necessary to achieve bringing the solution of the problem from the IOI archive to the critical score for the age group. As a result, according to the basic training (IOI qualification), each participant at the Junior and senior group level must already demonstrate the solution of problems to the full score (even with repeated approaches to the solution). It is very important that the participant has sufficient experience in solution tasks from the IOI archive for a full score and demonstrates the analysis skills these tasks and solve them again in a very short time at speed.

Group consultation with the coach. 1 hour. General discussion of tasks, identification of Syllabus topics for these tasks, and distribution of IOI tasks (subtasks to them) by age groups.

\section{The second week, 6 days.}

- Days 1-4, 10 hours. Home / independent work. Self-completion mode for the full score of the tour tasks and thinning out the selected 3 tasks from the Olympiad archive. Filling in the final table of indicators. Preparation of the analysis of 3 problems on the topics of the syllabus. The tasks analysis card includes: which topic of the Syllabus IOI is the task, what algorithm use for this task, and estimation of the complexity of the algorithm. 
- Day 5, 2 hours. Seminar on the results of the week of homework. Analysis of home independent work. Presentations of students on tasks with independent analysis. Group consultation with the coach.

- Day 6, 2 hours. English language training, reading and analysis of task texts in English from the IOI tasks archive and other Olympiads with the participation of a coach. Brainstorming on approaches to solving these problems.

\section{Starting and Planning Competence of the Participants of the National Olympic Reserve School}

Trainings can be organized in the country in the form of winter and summer schools and distance sessions between them.

The focus-group of training is juniors (13-15 years old) include 3 training cycles within three years to achieve planned competencies based on the formation of a culture of independent work. Seniors group (16-18 years old) select at result of working with juniors after 3 years sessions, training with seniors is carried out on an individual route with a personal trainer and a serious training plan for the results of higher achievements.

The selection of successful juniors is made from the primary group. It is important to conduct for this selection a mass school stage of the national Olympiad in Informatics, where successful children of 12-13 years old are identified, and a national team of juniors is formed for training sessions for them of the national Olympic reserve school and their promotion to higher achievements.

With young students ( $7-12$ years old), the work is carried out in primary groups in schools in their places of study with the involvement of children in online competitions. For younger students, it is important to master the course in Informatics and introduce syllabus topics based on problems in logic, combinatorics, graphs, as well as to master the programming of simple algorithms in $\mathrm{C}++$ at the user level. Summer and winter sessions for primary groups are held in their schools. For this purpose, teachers of these primary students must have an Olympiad mentor, with whom they can consult at any time, including Internet communication line, and have methodological materials and sets of tasks for younger students about Olympiad training.

Training camp of the national Olympic reserve school for juniors and seniors are best conducted together.

This School for junior and senior students is held as an Olympiad Informatics camp for national teams. Age of participants is supposed 13, but to be not older than 16 years by the end of the year. The student can choose the level of training: advanced (A) or base (B). The content of classes of the school of winter and summer schools is based on the thematic sections of the Syllabus IOI "6.2 Algorithms and Complexity (AL)".

IT clubs on the use of IT in various fields of science and technology is to form a space of formation of profile interests at the junction of science and information technology. The School program provides Robot-club. 


\section{Coach-group of the national Olympic reserve school:}

- Trainers of the national Olympiad in Informatics, coaches in Algorithms, IOI tasks coaches, $\mathrm{C}++$ programming teacher, specialist in the competition system.

- MOOC-tutor, consultant on new digital professions and it development prospects, General digital literacy coach or digital curator (Tsvetkova and Kiryukhin, 2019).

- Robot-club coaches (samples of application of programming in engineering).

- additional coaches in chess algorithmic games (origami, Rubik's cube, Go game, etc),

- Sports coach, educational psychologist for the junior and senior teams.

Start-competence of new participants of the national Olympic reserve school (juniors 12-14 years old):

- Knowledge of the subject of Olympiad tasks at the level of the National Olympiad in Informatics, high results at the school stage Of the National Olympiad in Informatics.

- Primary experience in solving simple problems of Olympiad Informatics (national Olympiad level, or levels of simple problems in the IOI task collection). Select a simple task from the collection can be based on the statistics of its solutions to the full score, in the Statistics section on the IOI website (IOI , 2019).

- Introduction to the themes of Algorithms.

- Availability of primary experience of participation in online Olympiads in Informatics.

- Ability to use the system of competitions, to send the decision for check, to test the decision.

- Primary $\mathrm{C}++$ programming skills.

- Ability to speed input on the keyboard Planned personal Junior skills on ISIJ The individual plan of the Olympiad training (for the period of 2-3 years) is focused on the independent work of the Junior with the resources of the Olympiad Informatics taking into account the specific tasks of IOI and syllabus IOI.

Planned competence of participants of the national Olympic reserve school (15-16 years old ):

- Knowledge of the IOI Syllabus.

- Ability to analyze the problem and determine the theme of the Syllabus IOI for the tasks.

- Experience in solving problems of increased difficulty theme.

- Knowledge of the criteria of self-assessment of achievements based on solving problems of increased difficulty, the ability to conduct self-analysis on the results of training, to set tasks to eliminate the identified deficiencies.

- The use of MOOC for development of the Olympiad in Informatics, Algorithms, data Structures, Programming.

- Readiness to solve the tasks of summer and winter school for daily training the practice on a full score. 
- Ability to identify difficulties in solving the problem in the first approach to it, the ability to find and study the theoretical material and analysis of solutions on the basis of the first approach to eliminate deficiencies, the ability to bring the solution of the problem after the second/subsequent approaches to a full score.

- The ability to build the personal training plan for the 2-3 years (a daily 2 - hour lesson on the tasks, in a remote environment, the ability to implement your plan without missing).

- The ability to work out high-speed problem solving skills (Yandex. Contest, 2018) repeated solution of one problem after its solution and analysis for a full score not more than 1 hour.

- Regular participation in a MOOC to improve the skill of programming in $\mathrm{C}++$ (for example Cursere, Cisco Networking Academy).

- Regular participant in online Olympiads.

- Elimination of difficulties in the English-speaking environment of the competition system and Olympiad tasks.

- The ability to analyze the text of the problem, the ability to analyze in the group solutions for subtasks and complete solutions.

- Fluency in work with systems of competitions in Informatics.

- The experience of creativity to develop algorithmic problem and legend-text of task and tests-set for the tour (work in a group with a coach), its full preparation for inclusion in the tour.

- The communication culture skills with colleagues.

- Understanding the value of active rest and sports for the programmer, compliance with the time for recreation and creativity in the application environment.

- Knowledge in perspective professions in the IT sector.

\section{Conclusion}

10 top skill is a key tool for solving the coaching tasks described above and a guaranteed path to the success of purposeful talented children in Olympiad in Informatics.

As leaders of the Russian team at the IOI from 1989 to 2018, we offer coaches of countries to use the methodology of Olympic training received in Russia, modified and issued as a coaching technology for the years 2002-2018. Since 2017, we have implemented in Russia the selection of the Junior team for training as an Olympic reserve for the selection of teams for IOI and opened this experience to all countries at the international school of Informatics for juniors ISIJ (ISIJ, 2019), described the starting and planned competencies of juniors to prepare for IOI. ISIJ takes place every year in Russia, Kazan in the summer, but in the winter - in countries by request.

This method was implemented in the preparation of Russian teams, the coaching goals were achieved, Russian teams always took 4 medals at all IOI and had gold. Now when preparing juniors, in addition to the strong training of the senior team, a groundwork is laid for success for several years to come: the succession of medalists. The guarantee of success in the stable preparation of the country's team with the formation 
of a change of teams from juniors-gives a start for 3 years ahead, as demonstrated by the Russian team, consisting of former juniors since 2018, the result of gold medals in 2018 and in 2019 confirms the success of the methodology developed by us. All participants of the Russian team of the last years started their training as juniors from 12-13 years old using the method described above. It is important to keep the best experience, enrich it, and rely on the methodological achievements and experience of the older generation when changing team coaches in the country, which is inevitable for decades.

The result of this method is the current national system of preparation for IOI in Russia, which can be used by any IOI member country. We are open to sharing this experience, which can be implemented in the work of coaches for all IOI teams. Training in this method for Junior teams and coaching groups from the country can be held at the annual international school of Informatics ISIJ in Russia (Tsvetkova and Kiryukhin, 2018).

The authors want to thank the entire IOI community for this huge contribution that IOI has made over 30 years of work, and wish the new generation of team leaders-head coaches-not to lose valuable techniques created during this period of formation and development of IOI and national computer science Olympiads for schoolchildren in the world. I suggest using this experience and going forward with it, looking for new trips to maximize the creative potential of the participants of the Olympiad. The main thing is that participation in IOI on the basis of talent and hard work will become their important life competence for further creativity and professional success.

\section{Reference}

Kiryukhin, V.M. (2007). The modern contents of the Russian national olympiads in informatics. Olympiads in Informatics, 1, 90-104.

Kiryukhin, V., (2010) Mutual Influence of the National Educational Standard and Olympiad in Informatics Contents. Olympiads in Informatics, 2010, Vol. 4, 15-29.

Kiryukhin, V.M., Tsvetkova, M.S. (2010). Strategy for ICT skills teachers and informatics olympiad coaches development. Olympiads in Informatics, 4, 30-51.

Kiryukhin, V., Tsvetkova, M. (2011). Preparing for the IOI trough developmental teaching. Olympiads in Informatics, 5, 44-57.

Kiryukhin, V.M., Tsvetkova, M.S. (2014). The approach of early olympiad preparation "Olympic Lift”. Olympiads in Informatics, 8, 111-122.

Tsvetkova, M. , Kiryukhin, V., (2016) Concept of Algorithmic Problems for Younger Students Olympiads in Informatics. Olympiads in Informatics, Vol. 10, Special Issue, 67-78.

Tsvetkova, M., (2016) Informatics at Russian Primary School. Olympiads in Informatics, 2016, Vol. 10, Special Issue, 3-6.

Tsvetkova, M. , Kiryukhin, V., (2018) International School in Informatics “Junior” for IOI Training. Olympiads in Informatics, Vol. 12, 187-193.

Tsvetkova, M. , Kiryukhin, V., (2019) Digital curator. Olympiads in Informatics, Vol. 13, 237-240.

Yandex. Contest (2018) IOI Archive. https://contest . yandex.ru/ioi/?lang=en

ISIJ (2019). International school in informatics “Junior". http: //www . isi-junior . com

IOI (2019). International Olympiad in Informatics. Statistics. http://stats . ioinformatics .org/tasks/ 


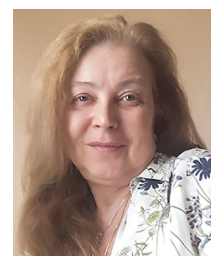

M.S. Tsvetkova, professor of the Russian Academy of Natural Sciences, $\mathrm{PhD}$ in pedagogic science, prize-winner of competition "The Teacher of Year of Moscow" (1998). Since 2002 she is a member of the Central methodical commission of the Russian Olympiad in informatics, the pedagogic coach of the Russian team on the IOI. She is the author of many papers and books in Russia on the informatization of education and methods of development of talented students. She is the author official textbooks and copybooks in Russia for primary school in Informatics. She is author and director International school in Informatic ISIJ (since 2017). She is the Russian team leader (2013-2017). She was awarded the President of Russia Gratitude for the success organizing the training of IOI medalists (2016). Expert of Committee on Education and Science State Duma of the Russian Federation (since 2017).

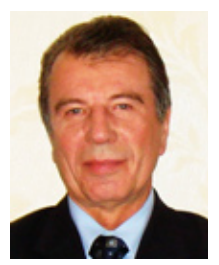

V.M. Kiryukhin is professor of the Russian Academy of Natural Sciences. He is the author of many papers and books in Russia on development of Olympiad movements in informatics and preparations for the Olympiads in informatics. He is the exclusive representative who took part at all IOI from 1989 to 2017 as a member of the IOI International Committee (1989-1992, 1999-2002, 2013-2017) and as the Russian team leader (1989, 1993-1998, 2003-2012). He received the IOI Distinguished Service Award at IOI 2003, the IOI Distinguished Service Award at IOI 2008 as one of the founders of the IOI making his long term distinguished service to the IOI from 1989 to 2008 and the medal " 20 Years since the First International Olympiad in Informatics" at the IOI 2009. He was chairmen IOI 2016 in Russia, and has the award medal of the President of Russia (2016) for organizing the Olympiad in Informatics in Russia and training IOI medalists since 1989. President of the international organizing Committee ISIJ. 